\title{
Numerical Investigation of the Particle Skeleton of Widely Graded Soils prone to Suffusion
}

\author{
P. Winkler, H. Jentsch, M. R. Salehi Sadaghiani, K.J. Witt \\ Bauhaus-Universität Weimar, Department of Geotechnical Engineering, Weimar, Germany
}

\begin{abstract}
The soil structure affects directly the capability of distributing and transmitting forces between its particles. Thus, the particle arrangement dictates the performance of soil under hydraulic and dynamic loads. This paper describes an analysis method in which the skeletal force chains of the particle assembly (packing) can be identified based on Discrete-Element-Method (DEM) modelling. For the simulations the software LIGGGHTS is used. A widely graded particle size distribution (PSD) is investigated to find correlations between PSD and the micromechanical properties of the particle assemblies. These PSD is based on common internal stability criteria prone to suffusion.

The different roles of fractions of the PSD in packings and the force chains under specified load are analysed. Therefor a packing is generated with the Modified-Force-Biased-Algorithm (MFBA). A method based on the bimodality of widely graded PSDs is proposed to differentiate the soil skeleton and the fill of packings of such a PSD. Particle contact number and contact forces are evaluated to identify the amount of loose particles, which are potentially mobile particles. The influence of the packing homogeneity on its skeleton is also addressed. The described method provides a better understanding of the soil structure as well as of internally stability of widely graded soil.
\end{abstract}

\section{INTRODUCTION}

Soil is an assembly of particles. Under load these particles pass forces to their neighbours in terms of contact forces. The particles size, shape, surface and material properties will influence the network of contact forces. For the assessment of the soils capability to withstand erosion this study is focused on the distribution of these forces. The effect on the resistance of the particles against drag of seepage is not considered. To take a detailed view on the forces between the particles we have to switch from the macro to the micro scale to get an insight of the soil in aspect of internal erosion, especially suffusion.

In the research field of suffusion a lot is already achieved (Terzaghi 1922, Ziems 1967, Kenny \& Lau 1986, Burenkova 1993, Wan \& Fell 2008, Witt 2013). There is a small field of problematic soils, which are widely graded. The main difference causing the problems is the diameter range of the particles. The more the maximal and minimal diameter of the particles differ, the more effort is necessary to assess the soil in aspect of suffusion and other erosion phenomena. To take this in concern, based on the bimodal structure theory of widely graded soil (Witt 2013) the influence of the effect of the forces is reduced to the ratio of the sizes of the particles. To compare the results to our experiments on artificial soil of glass beads (Jentsch et al. 2016) the common assumption of spherical particles shape (O'Sullivan 2011) is made, the surface and material properties are set the same for all particles. The discrete nature of soils establishes a non-continuous and discrete load transfer behaviour. This kind of behaviour is re-

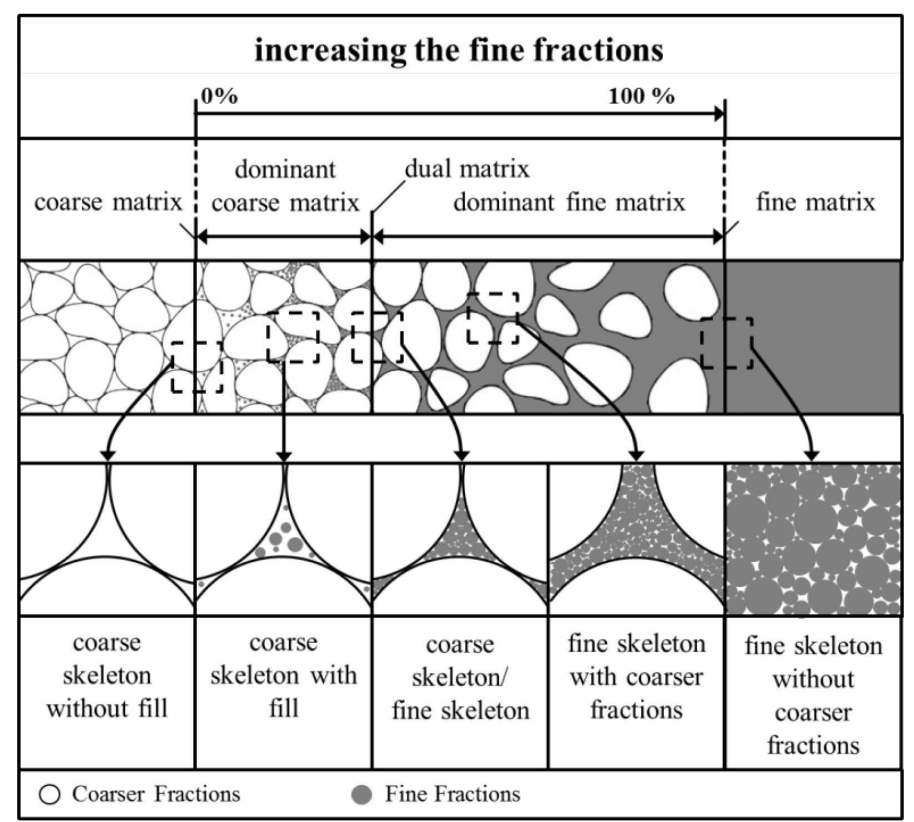

Figure 1. Type of matrix for granular packings (Jentsch 2016) 
lated to the particle assembly in microscale (Oda et al. 1982), which can be called the matrix. In the past, many researchers (Oda 1972a, Cundall \& Strack 1979, Mitchell \& Soga 2005) worked on the linkage of the matrix to the mechanical response of the particulate media, concentrating on describing the packing state and distribution of particle contacts.

It is difficult to determine the parameters of a granular packing by experimental means, because with the common state of technology, the materials internal structure cannot be observed without destruction. Therefore numerical simulations can be used to gain information about micro mechanical behaviour and to facilitate development of a micromechanics-based constitutive model of discrete materials. Unlike physical and analytical models, numerical simulations can provide essentially any desired piece of information (stresses, strain, detailed micromechanical statistics, and spatial distribution of matrix parameters) at any step during loading (Salehi Sadaghiani et al. 2014; Winkler et al. 2014).

\section{DEM-MODEL}

The DEM has become a common tool analysing soils structure (Cundall \& Strack 1979) with spherical particles (O'Sullivan 2011). Many parameters of the packing and its discrete particles can be obtained using DEM-models. To link the results of the numerical simulation to those encountered in field situations it is important to use a representative element volume (REV) (Salehi Sadaghiani et al. 2014).

For investigations on internal erosion, especially suffusion, it is important to identify the structure of the soil skeleton and fill. Therefore the packing of the soil should have the certain characteristic, like bulk density and porosity. For that reason packing generation with the intuitive approaches is not promising. The sequential methods like sedimentation algorithm or random sequential addition generate very loose packings which are not suitable for modelling soils with an porosity below $35 \%$. An approach like collective particle rearrangement which after Elsner (2009) is proper for the generation of dense packings can be used for generation of packings of the soil. The method is based on the algorithm of Jodrey \& Tory (1985), which was initially developed for monodisperse packing. Mośiński \& Bargiel (1989) extended this method to the Forced-BiasedAlgorithm (FBA). This algorithm is used in a modified form to meet the requirements for polydisperse packings and implemented in the open source DEM Code Liggghts (Kloss \& Goniva 2011), so we call it Modified-Force-Biased-Algorithm (MFBA). To reduce the particle numbers, and so the computational effort, and full fill the recommendations of the REV it uses periodic boundaries. To avoid segregation and get a isotropic and stochastic homogenous pack-

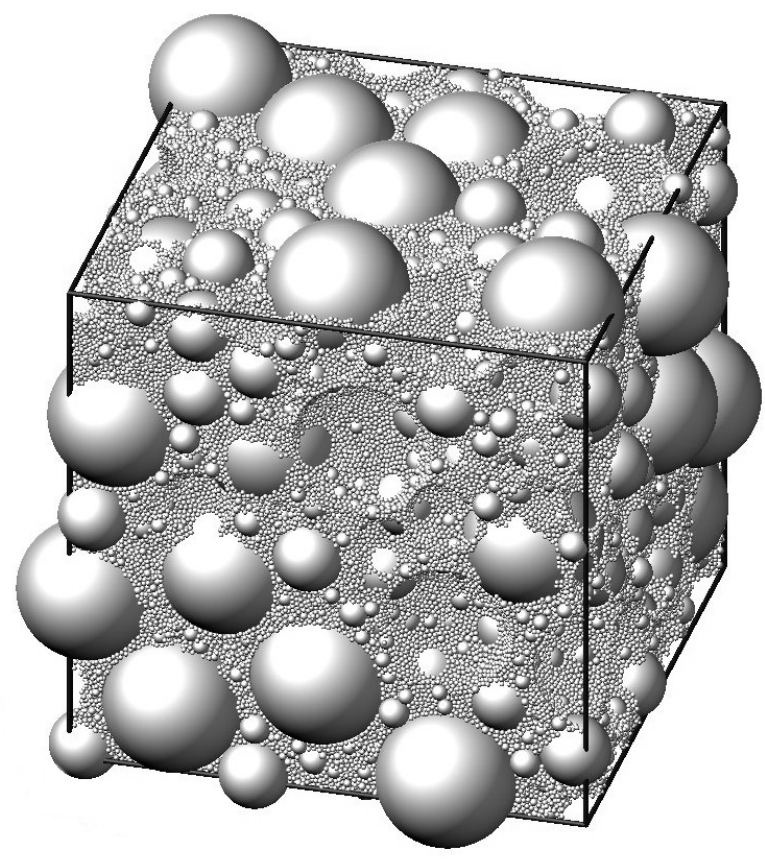

Figure 2. Close Random Packing generated with the MFBA

ing a gravitational force is not applied. The compaction of the packing is achieved by particle growth. The resulting contact forces cause a subsequent rearrangement of the particles (Winkler et al. 2014). The growth of the particles is controlled by a confined pressure referring to a compaction energy similar to the Proctor-test. This compaction energy is stored in the packing and results in a confined pressure which causes the particle contact forces. The rearrangement goes on until the particles overlapping has minimised to a tolerable value. In Figure 2 a polydisperse packing representing a widely graded

Table 1. Particle Size Fractions of PSD1

\begin{tabular}{lllllll}
\hline Fraction: & $\# 1$ & $\# 2$ & $\# 3$ & $\# 4$ & $\# 5$ & $\# 6$ \\
Diameter [mm]: & 27.0 & 13.5 & 5.86 & 2.99 & 1.48 & 0.9 \\
\hline
\end{tabular}

Table 2. Parameters for the DEM simulation using the MFBA

\begin{tabular}{lll}
\hline Parameter & Value & SI-Unit \\
\hline $\begin{array}{l}\text { Simulation box } \\
\text { Boundaries }\end{array}$ & $\begin{array}{l}0.1 \text { x } 0.1 \times 0.1 \\
\text { periodic }\end{array}$ \\
Gravity & no & \\
Time Step Length & $10 \mathrm{e}-7$ & $\mathrm{~s}$ \\
Granular Model & Hertz (tangential history) \\
Particle Diameter & $27-0.9$ & $\mathrm{~mm}$ \\
Particle Number & up to 320,000 & \\
Young's Modulus & 50.0 & $\mathrm{GPa}$ \\
Poisson's Ratio & 0.35 & - \\
Coefficient of Restitution & 0.5 & - \\
Coefficient of Friction & 0.5 & - \\
Coefficient of Rolling Friction & 0.001 & - \\
Cohesion Model & simplified J-K-R \\
Cohesion Energy Density & $3.0 \mathrm{e} 5$ & $\mathrm{~J} / \mathrm{m}^{3}$ \\
\hline
\end{tabular}


soil generated by the MFBA is shown. This method matches very well the complicated behaviour of a dense, polydisperse packing for a given PSD (Winkler et al. 2015).

A major problem of the numerical simulations is the enormous computational effort, rising with the number of particles. The most important and most challenging issue on widely graded soils is the relation in size of the coarsest $\left(\mathrm{d}_{\max }\right)$ to the finest $\left(\mathrm{d}_{\min }\right)$ particle fractions. Particle assemblies with a ratio of 1.0 are called monodisperse, all particles are of the same size. The higher the ratio, the more the assembly gets polydisperse. The big variance in particle size entail a high number of small particles. Since the widely graded soils which are prone to suffusion, are gap graded, the fine fractions claim a high percentage of mass and a still higher share in particle number. Because the major essence of the widely graded soils is the polydisperse manner and wide range of the particle size, this work focuses on PSD1, which is shown in Figure 3. The PSD is represented by 6 particle size fractions in the range of 27 to $0.9 \mathrm{~mm}$ which gives a ratio of $d_{\max }$ to $d_{\min }$ of 30 . In Table 1 the particle size fractions are named. Regarding the REV this is the packing with the widest range at the moment generated with the MFBA. A wider range will cause higher particle numbers, which increase the computational effort over a sensible limit. In Table 2 the essential parameters of the DEM model are summarised.

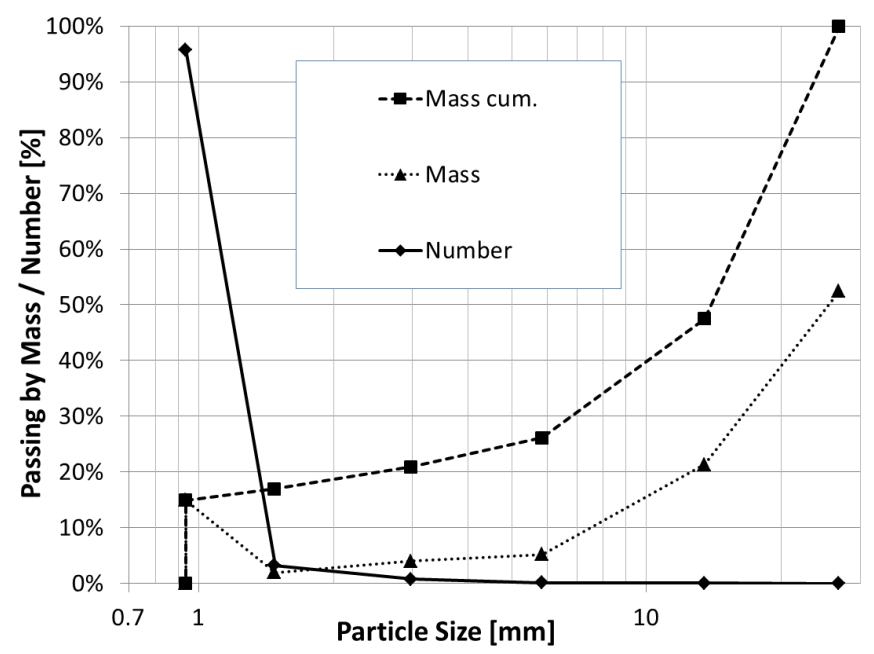

Figure 3. PSD of PSD1 with particle size fractions

\section{NUMERICAL SIMULATION}

The numerical simulation can afford a detailed view inside the micromechanical behaviour of the packing of the widely graded soils. It provides the geometric data (particle coordinates, size and velocity) and a lot of additional parameters (contact number, stresses). Also the information about every single contact (data on involved particles, force vector, distance vector) are obtained. Since the particles have

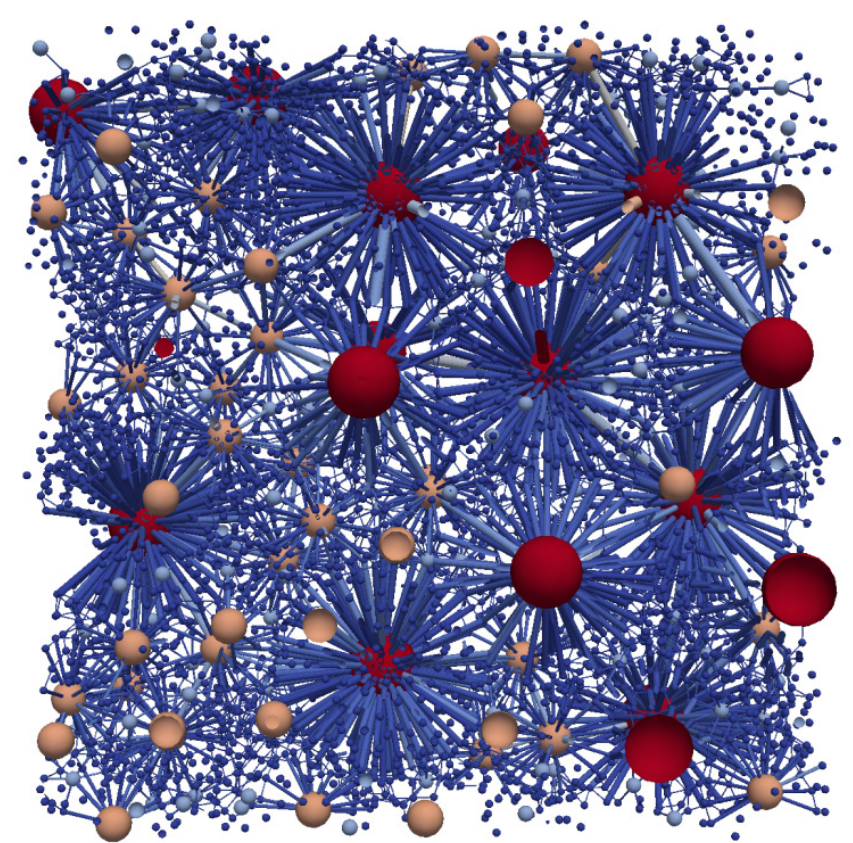

Figure 4. Network of particle forces, particles are scaled-down

multiple contacts, the volume of the contact data is about average contact number higher than the particle data. This will generate a lot of data, storing the progress of the packing over the simulation time. The simulation of PSD1 contains the data of 320,000 particles and ca. 1 million contacts at 119 moments. This data has to be analysed. Therefor normal spreadsheets are not suitable. For analysing the amount of data tools were written in the programming languages python and $\mathrm{C}++$.

The primary objective was to examine the distribution of contact numbers and contact forces over the particle size to assess the assumption of the bimodal theory. The particle based data was condensed to some parameters for every particle size fraction. The parameters are mainly 3-dimensional force vectors, their magnitudes and averages referring to the particle size fractions.

In second position the properties of the particle contacts were analysed and the relations between the particle size and contact forces were determined. The interacting particles of a contact are ascertained and the number and forces of the contacts per combination of the particle size fractions are evaluated. Not only the network of forces, which identifies the skeletons particles of the packing, also the micromechanical relations between the particle size fractions can be analysed.

To ensure that the observed behaviour of the packing represents the characteristics of the PSD investigated, the packing was divided in sections and the deviation of the PSD for each section checked. Hence the stochastic homogeneity can be easily assessed.

To visualise the network of the particle contact forces, the data was rendered in the visualization application ParaView (Fig. 4). It gives a picture how the forces are accumulated at the coarse particles. 


\section{RESULTS}

The distribution of the contact numbers (Fig. 5) and contact forces (Fig. 6) over the particle size are shown in diagrams. Remind that $96 \%$ of the particle number account for the finest fraction \#6. While the average contact number per particle (Fig. 5) is the highest for the coarsest fraction \#1, the total number of contacts is dominated by the fraction \#6. This is caused by the ratio of the particle surface. Since the coarsest particles are 30 times bigger than fraction \#6, they will have a surface multiplied by 900 , which gives more place for neighbours and contacts. A similar picture is given by Figure 6 for the contact forces. The highest average contact force by particle is reached by the coarsest fraction \#1, yet the majority of the total contact forces in the packing is carried by the finest fraction \#1. This seems contrary to the assumption of the bimodal theory, supposing a skeleton of the coarse particles and a fill consisting of the finer fractions. In order to pursue this, the particles involved in the contacts are moved into focus.

To show the number of combinations of the particle fractions in Figure 7 a heat map is shown. The darker areas indicate higher values. Very clearly the contacts amongst the smallest particles of fraction \#6 dominate the packing by number. $65 \%$ of the contacts in the packing are contacts of the smallest particles. In Figure 8 the average contact forces between the particle size fractions are depict. The contacts of the coarse fractions dominate the per

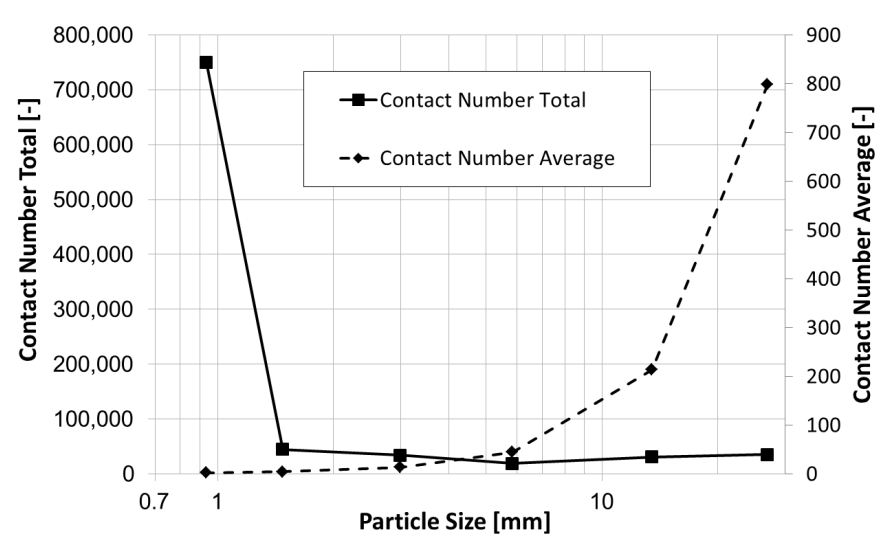

Figure 5. Diagram - Contact Number over Particle Size

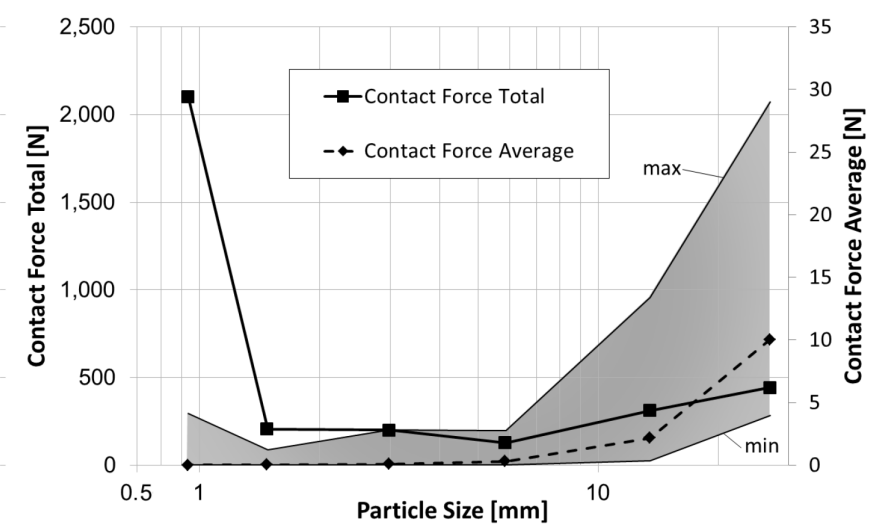

Figure 6. Diagram - Contact Force over Particle Size
\#

$\#$

\#2

\#3

\#4

\#5

\#6

Figure 7. Number of Contacts between Fractions [-]

\begin{tabular}{ccc|c|c|c|c} 
& \#1 & $\# 2$ & $\# 3$ & $\# 4$ & $\# 5$ & $\# 6$ \\
\hline \#1 & $10,293.7$ & $4,612.8$ & 802.5 & 31.5 & 7.8 & 10.0 \\
\hline \#2 & & $2,876.1$ & 513.3 & 63.1 & 4.7 & 3.1 \\
\hline$\# 3$ & & & 187.5 & 28.2 & 2.4 & 1.7 \\
\hline$\# 4$ & & & 8.9 & 5.0 & 4.3 \\
\hline \#5 & & & & 3.3 & 3.9 \\
\hline \#6 & & & & & & 4.6 \\
\hline
\end{tabular}

Figure 8. Ave. Contact Force between Fractions [N]

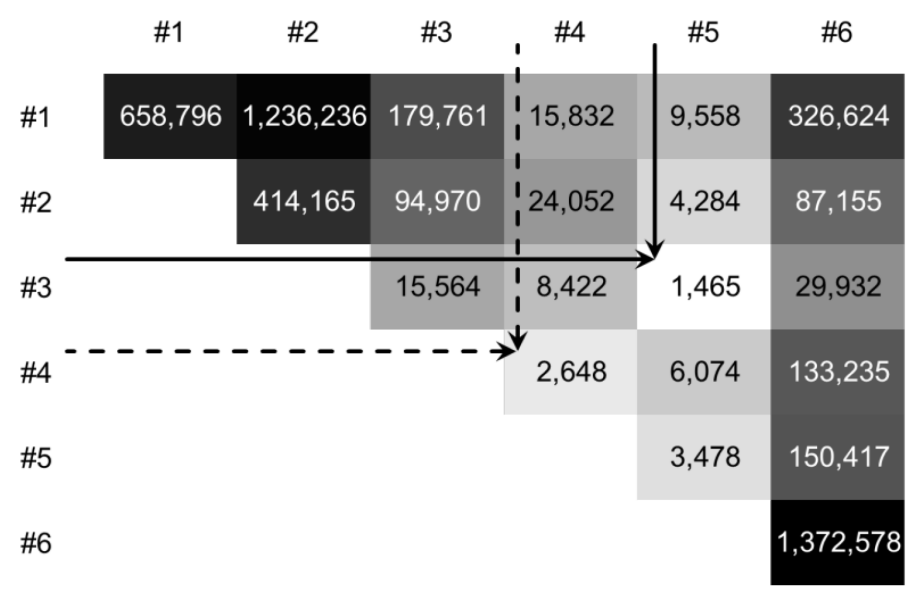

Figure 9. Total Contact Force between Fractions [N]

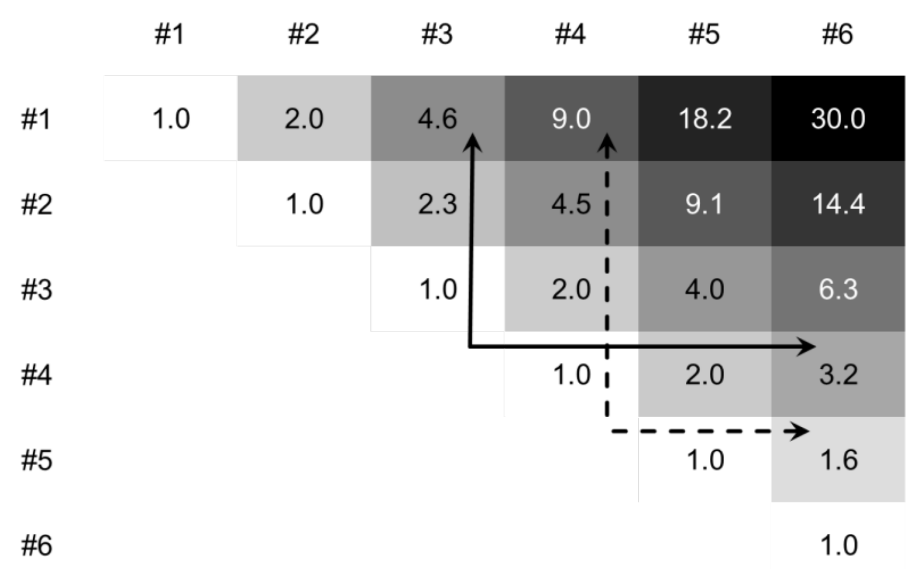

Figure 10. Ratio of the Particle Diameter of the Fractions [-] 
particle forces, which shows that the coarse particles are exposed to high stresses. In the next heat map (Fig. 9) the total forces of the combination of the particle size fractions are shown. There are two dark areas. One hot spot is the combination of particles of fraction \#1 with \#2, but a still higher level of absolute contact forces of the packing are observed at contacts amongst fraction \#6. The author assumes that particles are transmitting load preferred to particles of the same size. The lowest total contact forces are between the particles of fraction \#3 and \#5. The second lowest total contact force occurs amongst particles of fraction \#4. Obviously there is a deviation of the middle sized particle fractions. To examine if the behaviour of fraction \#4 and \#5 is caused by the minor average differences in size to the other fractions (what is implied in the nature of the middle sized particles), in Figure 10 the ratio of the particles diameter of every fraction is calculated. Fraction \#3 has the most narrow range of diameter ratio of maximal 6.3 to fraction \#6. The gap of fraction \#5 cannot just be explained with the particle size ratio, but they seem not well included in the skeleton of the packing.

This brings us to the distribution of the particles contact forces within the fractions. Thereto a histogram of the average contact force of the particle size fraction for 11 intervals of $20 \%$ is depicted (Fig. 11). The interval of $100 \%$ complies to the average value of the fractions contact force. Since the trends of fraction \#3 and \#5 fit in the pattern, for clarity they are neglected. The finer the fraction, the higher the proportion of particles in the fraction with low to no contact forces. In fraction \#6 39\% of the particles share less than $20 \%$ of the average contact force of the fraction. So a higher percentage of particles in the finer fractions is not involved in the skeleton. These particles are loose in the assembly and potentially mobile. The particles of the coarser fractions show rather a curve like the assumed normal distribution. The curves meet at the upper range of the contact force and share the same percentage of outlier. Through the discrete nature, the finer the fractions, the higher the particle numbers and the

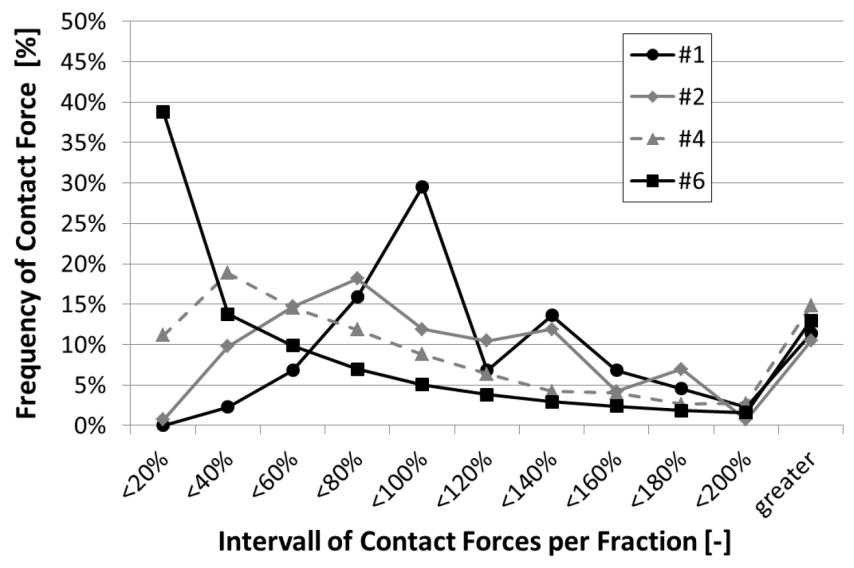

Figure 11. Histogram of Contact Forces by Particle

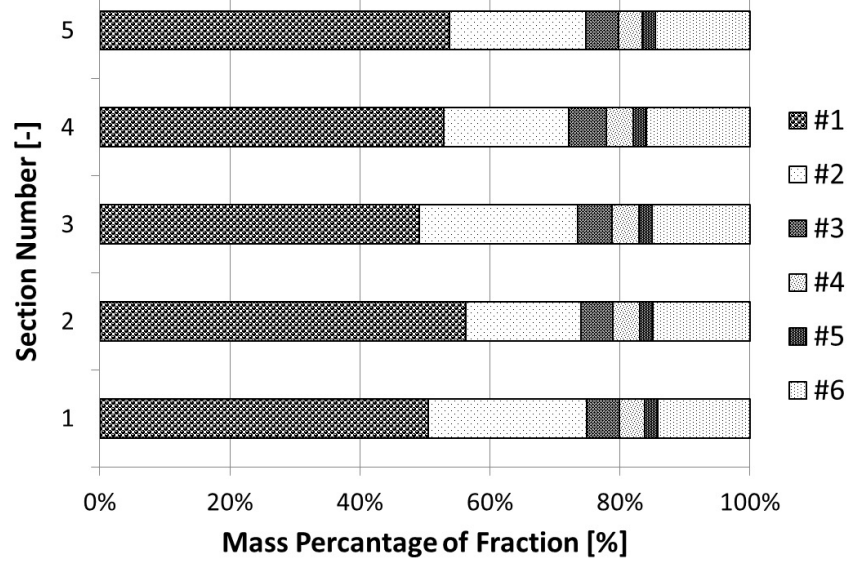

Figure 12. Deviation of the PSD in the Sections

smoother gets the curve. To estimate the quality of the results, the homogeneity of the packing, as a spatial distribution of the particles, is considered. To assess the deviation of the porosity the coefficient of variation $(\mathrm{CV})$ is used. The $\mathrm{CV}$ is about $3 \%$. For the deviation of the PSD, the particle numbers in the sections are counted. The highest deviation shows fraction \#2 with a CV of $14 \%$, which after Phoon (2008) is still a good result. For the finer fractions a $\mathrm{CV}$ of $5 \%$ is achieved. Figure 12 gives an overview about the deviation.

\section{CONCLUSION}

With the numerical simulation of random close sphere packings generated with the MFBA the load carrying particles of the soils skeleton are identified. The distribution of the contact forces over the particle size fractions and the amount of fill and skeleton in the packing, depending on the particle number of the fraction and the ratio of the size of the particle fractions, can be quantified. The results approve the bimodal theory, but without a sharp boundary of skeleton and fill. Rather there is a steady transition of the coarse skeleton to a next finer ones over the whole PSD. Through the higher number of particles and contacts, the finer skeletons have more capabilities of rearrangement, which results in a lower stiffness. The polydisperse sphere packings have multiple skeletons with different stiffness which permeate and influence each other. The coarse particles of the primary fabric carry in total less load than the sum of all the smallest particles. Of course, removing a coarse particle will change the ability of load carrying more than removing one fine particle, but removing the same mass of fine particles like the mass of one coarse particle will make an even bigger change. That it is the reason why the assessment and to prevent suffusion is so important and not just because the loss of fine particles results in a decrease of volume, which will allow a rearrangement of the primary skeleton. If all particles are involved in the 
skeletons of the packing suffusion cannot occur. In widely graded soils which often are gap graded the transition between the skeletons of different scale can be disturbed, also in locally segregated areas of the packing this may appear. Such a weak spot can be seen in Figure 9 at the interaction of fraction \#3 and fraction \#5. The wider the range off the particle size, the greater the problem. If the graduation of the particles in the packing allows the transition of the skeletons, every particle is involved in a skeleton, else there are some potentially mobile particles. If the pore path is wide enough they could be washed out by the drag of the seepage water.

\section{PREFERENCES}

Burenkova V.V. (1993): Assessment of suffusion in noncohesive and graded soils. Proc.1st.Int.Conf.GeoFilters, Karlsruhe, Germany, Balkema, Rotherdam, Netherlands, 357360.

Cundall P.A., Strack O.D.L. (1979): A Discrete Numerical Model for Granular Assemblies, Géotechnique, 29: 47 -65.

Elsner A. (2009): Computergestützte Simulation und Analyse. TU Bergakademie Freiberg, 2009.

Jentsch H.; Saheli Sadaghiani M.R.; Winkler P. \& K.J. Witt (2016): Experimental Identification of the Dominant Fabric in Widely Graded Soils. Proc. of the 8th.International Conference on Scour and Erosion (ICSE-8), 12.-15.09.2016, Oxford, UK.

Jodrey, W.S., Tory, E.M. (1985): Computer simulation of close random packing of equal spheres. Phys. Review A: Atomic, Molecular and Optical Physics, 322347 - 2351.

Kenny, T. C. \& Lau, D. (1986): Internal stability of granular fil-ters: Reply. Canadian Geotechnical Journal, 23, 420423.

Kloss C., Goniva C. (2011): LIGGGHTS an Open Source Discrete Element Simulations of Granular Materials based on LAMMPS, Proc. TMS Annual Meeting, San Diego.

Mitchell, J.K., \& Soga, K. (2005): Fundamentals of soil behavior. Hoboken, N.J: John Wiley \& Sons.

Mościński J., Bargiel M., Rycerz Z. A., Jacobs P. W. M. (1989): The Force-Biased Al-gorithm for the Irregular Close Packing of Equal Hard Spheres. Molecular Sim., $3: 201$.

Oda M., Nemat-Nasser S., Mehrabadi M. M. (1982): A Statistical Study of Fabric in a Random Assembly of Spherical Granules. J. Num. Anal. Meth. Geomech, 6, 77 -94.

Oda, M. (1972a): Initial fabrics and their relations to mechanical properties of granular materials, Jap. Soc. Soil. Mech. Fdn. Engng, 12(1), 17-36.

O'Sullivan, C. (2011): Particulate Discrete Element Modelling - A Geomechanics Perspective. Spon Press.

Phoon, K.K. (2008). Reliability-Based Design in Geotechnical Engineering: Computations and Applications. Abingdon: Oxon.

Salehi Sadaghiani M.R., Jentsch H., Winkler P., Witt K.J. (2014): DEM Modeling and Identification of Representative Element Volume of Soil Skeleton. NUMGE 2014. Delft, Holland.

Terzaghi (1922): Failure of dam foundations by piping and means for preventing it., Die Wasserkraft, Zeitschrift für die gesamte Wasserwirtschaft, 17(24), p. 445-449.

Wan C. \& Fell R. (2008): Assessing the Potential of Internal In-stability and Suffusion in Embankment Dams and Their Foundations. Journal of Geotechnical and Geoenvironmental Engineering, 134, 401-407.
Winkler P.; Salehi Sadaghiani M. R.; Jentsch H. \& Witt K. J. (2014): Granular packing generation using DEM - Modified Force-Biased-Algorithm. Proceedings of the 7th.International Conference on Scour and Erosion (ICSE7), 02.-04.12.2014, Perth, Australia, pp.345-349

Winkler P., Saheli Sadaghiani M.R. \& K.J. Witt (2015): Packing Generation using DEM - Comparison of Methods. Proceedings of the Morphodynamics 2015 Workshop, 22.09.2015, Hamburg, Germany, pp.71-78.

Witt, K. J. (2013): Das Selbstfiltrationsindex als Suffosionskrite-rium für nichtbindige Erdstoffe. Geotechnik, 8.

Ziems (1967): Neue Erkenntnisse hinsichtlich der Verformungsbeständigkeit der Lockergesteine gegen-über Wirkungen des Sickerwassers, WasserwirtschaftWassertechnik, 17. Jahrgang, Heft 2, S. 50-55.

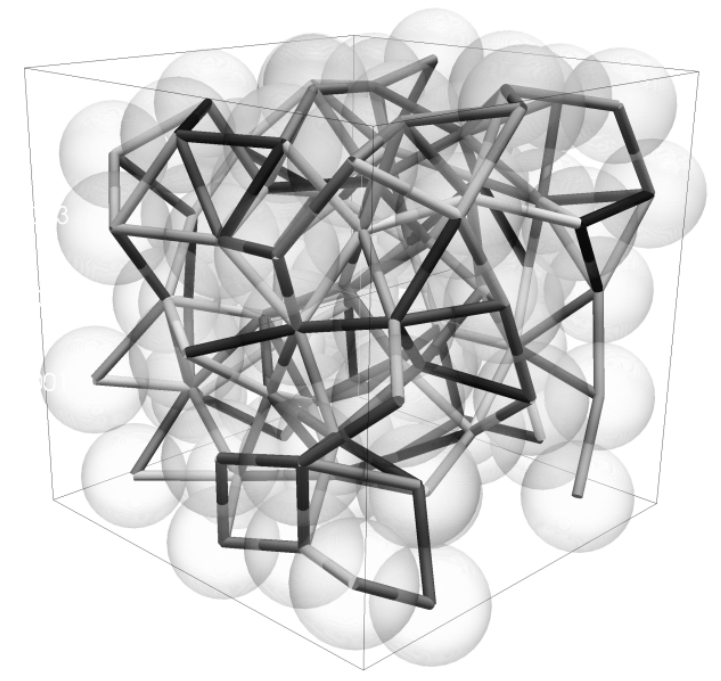

